\title{
Flood Disaster Risk Assessment and Spatial Distribution Characteristics along the Yangtze River in Anhui Province
} Xianfu Cheng ${ }^{1,2}$, Honghu Sun ${ }^{1,2}$, Zhang Yuan ${ }^{1,2}$, Guanglai Xu ${ }^{1}$

\author{
1. College of Territorial Resources and Tourism, Anhui Normal University, Wuhu 241003, China
}

2. Anhui Key Laboratory of Natural Disaster Process and Prevention, Wuhu 241003, China

Received 20 January 2014

Accepted 14 September 2014

\begin{abstract}
Using analytic hierarchy process and entropy method to determine the weight of index, fuzzy comprehensive evaluation model of risk assessment was constructed in this paper. Flood risk index and risk rating of area along the Yangtze River in Anhui province were drawn by using GIS spatial analysis technology. From disaster causing factors, inducing environment and bearing body, average maximum 3 day rainfall, rainstorm number, vegetation coverage, river network density, standard deviation of the elevation, population density, proportion of rural population, density of GDP, per capita net income of farmers, and cultivated land area ratio were selected as evaluation indicators. The results show that flood risk rating and risk index of area along the Yangtze River in Anhui province has a spatial distribution characteristics from south to north gradually reduced.
\end{abstract}

Keywords: Flood Disaster; Risk Assessment; Comprehensive Assessment; Spatial Distribution, Anhui Province

\section{安徽沿江地区洪涝灾害风险评价与空间分布特征 程先富 ${ }^{1,2}$ 孙鸿鹄 $^{1,2}$ 张媛 $^{1,2}$ 徐光来 $^{1}$ \\ 1.安徽师范大学国土资源与旅游学院, 安徽 芜湖 241003, 中国 \\ 2.安徽自然灾害过程与防控研究省级实验室, 芜湖 241003, 中国}

\begin{abstract}
摘要: 本文运用层次分析法和熵值法确定指标的权重, 构建风险评价的模糊综合评价模型, 并利用 GIS 空 间分析技术绘制出安徽沿江地区洪灾风险指数图和风险等级图。我们从致灾因子、孕灾环境和承灾体三方 面选取平均最大 3 日降雨量、暴雨次数、植被覆盖率、河网密度、高程标准差、人口密度、乡村人口比重、 GDP 密度、农民人均纯收入、耕地面积比等 10 个评价指标。研究结果表明: 安徽沿江地区洪灾风险等级和 风险指数具有自南向北逐渐降低的空间分布特征。
\end{abstract}

关键词: 洪涝灾害, 风险评价, 综合评价, 空间分布, 安徽

\section{1. 引言}

随着全球气候变化和城市化进程的加快, 在自然 和人为因素的相互作用下, 暴雨、洪涝等气象灾害发 生的频率、强度越来越大, 造成的经济财产的损失越 来越严重。洪涝灾害的风险研究受到许多学者的广泛 关注, 并成为灾害科学研究的前沿课题 ${ }^{[1]}$ 。美国、日 本等发达国家早在20 世纪50、60 年代就开展了洪涝 灾害风险研究, 制作了国家级的洪涝灾害风险图 ${ }^{[2-5]}$ 。 我国从20 世纪80 年代中期开始开展洪涝灾害风险研 究, 并对一些蓄滞洪区、城镇、水库与流域进行洪涝 灾害风险图的绘制。

目前国内外对洪涝灾害风险评估开展了深入研 究。大多集中于风险概率的计算、风险指标体系的构
建与评估、风险建模与评估等三个方面 ${ }^{[6-8]}$ 。洪涝灾害 风险评价常用的数学方法有 ${ }^{[9-13]}$ : 统计分析方法、决策 分析法和综合评价法等。统计分析方法包括主成分分 析法、相关分析法、回归分析法和时间序列分析法, 其中回归分析法是比较常用的方法。这种方法的不足 之处在于当样本容量足够大时, 统计结果才比较可靠。 决策分析法中最常用的是层次分析法, 思路清晰且系 统性强, 所需定量数据较少, 对问题本质分析得较透 彻, 颇具实用性, 但具有主观性强的缺点。综合评价 法包括模糊数学、灰色系统和人工神经网络等。此外, 还有系统动力学方法、灾害风险指数法和基于扩散理 论的风险评价方法等。其中模糊综合评价法是采用模 
糊数学的方法进行综合评价, 克服了从多方面对事物 进行评价难免带有模糊性和主观性的缺点, 使评价结 果尽量客观从而取得更好的实际效果。

安徽沿江地区是安徽省经济较发达的地区。在全 球气候变化、城市化和人口与经济快速集聚的背景下, 该地区洪涝灾害发生较为频繁, 灾情日益严重。前人 在本区开展的研究主要集中在极端降水、径流、灾害 成因与规律等方面。如吴丹娃等 ${ }^{[14]}$ 分析了 2010 年安徽 沿江地区一次暴雨的中尺度特征; 张之丽 ${ }^{[15]}$ 分析了安

\section{2. 研究区域和数据来源}

\section{1 研究区概况}

安徽沿江地区位于安徽省南部, 处于 $116^{\circ} \sim$ $119^{\circ} \mathrm{E}, 30^{\circ} \sim 32^{\circ} \mathrm{N}$ 之间, 下辖马鞍山市、芜湖市、 铜陵市、池州市、安庆市、和巢湖市 6 个地级市 20 个 县, 总面积 $39025 \mathrm{~km}^{2}$, 占全省总面积的 $27.95 \%, 2008$ 年人口 1671 万人, 占全省总人口的 $24.8 \%$ 。属于亚热 带湿润季风气候, 夏季高温多雨, 冬季寒冷干燥。年 平均气温 $16-17.3^{\circ} \mathrm{C}$, 常年无霜期达 220-250d, 年平均 降水量 770-1700mm 之间, 降水量季节分配不均, 多 集中在 5-9 月, 地形以丘陵山地和平原为主。

\section{2 数据来源}

本文的气象资料来源于安徽省 78 个气象站点, DEM 数据来源于地球系统科学数据共享网 STRM 系 统 $90 \mathrm{~m}$ 空间分辨率，遥感数据为安徽沿江地区 2008 年 8 月 $\mathrm{TM}$ 影像, 经解译获得安徽沿江地区土地利用 图和植被覆盖率图。社会经济数据来自于安徽省统计 年鉴及沿江各县市的统计年鉴。

\section{3. 研究方法}

\section{1 指标体系的建立}

在分析安徽沿江地区地理特征的基础上, 依据洪 灾风险的相关原理, 遵循数据尽量空间化、技术手段 先进有效、指标体系可操作性强等原则, 从致灾因子、 孕灾环境和承灾体三个层面选取平均最大 3 日降雨 量、暴雨次数、植被覆盖率、河网密度、高程标准差、 人口密度、乡村人口比重、GDP 密度、农民人均纯收 入、耕地面积比 10 个评价指标, 构建安徽沿江地区洪 涝灾害风险评价指标体系。

\section{2 指标体系权重的确定}

分别用层次分析法和摘权法求得主观权重和客观 权重, 然后对主观权重和客观权重运用最小信息摘法 得到综合权重。AHP 确定评价指标权重的步骤如下: 采用 1 9 及其倒数的标度方法, 对两两元素相对重 要性程度进行量化。构造判断矩阵, 计算准则权重。 根据各层次所有元素的重要性权重值进行层次单排序 与总排序; 利用一致性指标 $(\mathrm{CI})$ 、随机一致性指标 $(\mathrm{RI})$ 和一致性比率 $(\mathrm{CR})$ 进行一致性检验。若 $\mathrm{CR} \leqslant 0.1$, 则
徽沿江诗区灾害的成因; 朱维民等 ${ }^{[16]}$ 探讨了安徽沿江 地区旱涝规律及其未来趋势。对洪涝灾害风险研究较 少。张海玉等 ${ }^{[17]}$ 应用模糊数学方法评价了安徽沿长江 地区洪涝灾害的经济易损性。本文根据巢湖流域的实 情, 选取评价指标, 建立评价指标体系和模糊数学综 合评价模型, 基于综合评价模型和 GIS 空间分析技术 对安徽沿江地区洪涝灾害风险进行评价, 揭示其空间 分布特征, 为沿江地区制定规划、灾害风险管理与可 持续发展提供科学依据。

判断矩阵具有满意的一致性。通过计算得到致灾因子、 孕灾环境和承灾体构成的判断矩阵的最大特征根为 3.0078, $\mathrm{CI}=0.0048, \mathrm{RI}=0.59, \mathrm{CR}=0.0077$, 表明一致 性较好。特征向量 (归一化后) 即为主观权重向量。

\subsection{1 求算评价指标的客观权重}

运用熵权法求算熵值，其公式如下：

$$
\begin{aligned}
& E_{j}=-\sum_{i=1}^{n} \frac{d_{i j}}{d_{j}} \ln \frac{d_{i j}}{d_{j}} \\
& d_{j}=\sum_{i=1}^{n} d_{i j} \\
& d_{i j}=\frac{D_{i j}}{\sum_{i=1}^{n} \sum_{j=1}^{m} D_{i j}}
\end{aligned}
$$

式中, $i$ 为评价单元; $j$ 为评价指标, $E_{j}$ 为第 $j$ 个 评价指标的熵值; $D_{i j}$ 为接近程度; $d_{j} 、 d_{i j}$ 为中间变量。

对于正向指标 $r_{j}^{*}=\max _{i}\left\{r_{i j}\right\} \quad D_{i j}=\frac{r_{i j}}{r_{j} *}$

对于负向指标 $r_{j}^{*}=\min _{i}\left\{r_{i j}\right\} \quad D_{i j}=\frac{r_{j}^{*}}{r_{i j}}$

如果 $E_{j}$ 越大, $\mathrm{j}$ 指标越重要, 则 $e_{j}=\frac{E_{j}}{\ln m} \quad \theta_{j}=\frac{e_{j}}{\sum_{j=1}^{m} e_{j}}$

如果 $E_{j}$ 越小, $\mathrm{j}$ 指标越重要, 则 $e_{j}=\frac{E_{j}}{\ln m} \quad \theta_{j}=\frac{1-e_{j}}{n-\sum_{j=1}^{m} e_{j}}$

式中, $\theta_{j}$ 为 $\mathrm{j}$ 指标的客观权重, $e_{j}$ 为中间变量。

\subsection{2 综合权重的确定}

根据最小信息熵原理，对主观权重和客观权重进 行运算从而得到综合权重。

$$
w_{j}=\left(w_{1 j} * w_{2 j}\right)^{\frac{1}{2}} / \sum\left(w_{1 j} * w_{2 j}\right)^{\frac{1}{2}}
$$

式中, $w_{j} 、 w_{1 j} 、 w_{2 j}$ 分别为 $\mathrm{j}$ 指标的综合权重、主 观权重和客观权重。

通过计算, 平均最大 3 日降雨量、暴雨次数、植 被覆盖率、河网密度、高程标准差、人口密度、乡村 人口比重、GDP 密度、农民人均纯收入、耕地面积比 的综合权重分别为 $0.3207,0.0406,0.0889,0.1401,0.1018$, $0.0805,0.0647,0.0548,0.0599,0.0480$ 。 


\section{3 模糊评价模型的建立}

选择标准差的平均值与均值的平均值中的最小值 作为指标数据模糊子集分级的间隔值, 每个指标数据 都有 5 个间隔点 (D1、D2、D3、D4、D5), 指标数据 分级标准见表 1 。植被覆盖率、高程标准差、农民人 均纯收入与洪涝灾害风险呈负相关关系, 故对其取倒 数，其对应倒数与洪涝灾害风险呈正相关关系。

$$
r_{i 3}=\left\{\begin{array}{cc}
0 & g_{i} \leq D 2 \text { 或 } g_{i} \geq D 4 \\
\frac{g_{i}-D 2}{D 3-D 2} & D 2<g_{i}<D 3 \\
1 & g_{i}=D 3 \\
\frac{D 4-g_{i}}{D 4-D 3} & D 3<g_{i}<D 4
\end{array}\right.
$$

表 1 指标数据分级标准

Table 1 Division standard of index data

\begin{tabular}{lcccccc}
\hline & 间隔值 & D1 & D2 & D3 & D4 & D5 \\
\hline 年均最大 3 日降雨量 $(\mathrm{mm})$ & 15.2 & 50.0 & 65.2 & 80.4 & 95.6 & 110.8 \\
暴雨次数 & 1.0 & 3.0 & 4.0 & 5.0 & 6.0 & 7.0 \\
植被覆盖率(取倒数) & 0.35 & 1.00 & 1.35 & 1.70 & 2.05 & 2.40 \\
河网密度 $\left(\mathrm{m} / \mathrm{m}^{2}\right)$ & 0.020 & 0.018 & 0.038 & 0.058 & 0.078 & 0.098 \\
高程标准差 $(\mathrm{m}$,取倒数) & 0.38 & 0.27 & 0.65 & 1.03 & 1.41 & 1.79 \\
人口密度(人 $/ \mathrm{km}^{2}$ ) & 235.67 & 167.43 & 403.10 & 638.77 & 874.44 & 1110.12 \\
乡村人口比重 $(\%)$ & 0.1072 & 0.4345 & 0.5416 & 0.6488 & 0.7559 & 0.9631 \\
GDP 密度 $\left(\mathrm{GDP} / \mathrm{km}^{2}\right)$ & 531.75 & 180 & 711.75 & 1243.49 & 1775.24 & 2306.98 \\
农民人均纯收入(元,取倒数) & 0.00004 & 0.00016 & 0.00020 & 0.00024 & 0.00028 & 0.00032 \\
耕地面积比 $(\%)$ & 6.45 & 6.15 & 12.60 & 19.05 & 25.50 & 31.95 \\
\hline
\end{tabular}

\section{4 隶属函数的建立}

根据研究区的实际情况, 并参考相关的研究成果, 运用分段线性函数确定洪涝灾害各个风险等级的隶属 函数。将洪灾划分为高风险区、较高风险区、中等风 险区、较低风险区、低风险区五级。其中高风险区基 于升半梯形函数, 低风险区基于降半梯形函数, 其余 等级区均基于三角形函数。根据指标数据分级标准及 分段函数, 本项目建立了洪灾风险统一的模糊子集。 $r_{i j}$ 表示第 $\mathrm{i}$ 个指标第 $\mathrm{j}$ 个风险等级的模糊隶属度, $g_{i}$ 表 示第 $\mathrm{i}$ 个指标的数值, 五个等级的隶属函数如下。

$$
\begin{gathered}
r_{i 1}= \begin{cases}1 & D 1 \leq g_{i} \leq D 2 \\
\frac{D 2-g_{i}}{D 2-D 1} & D 1<g_{i}<D 2 \\
0 & g_{i} \geq D 2\end{cases} \\
r_{i 2}=\left\{\begin{array}{cl}
0 & g_{i} \leq D 1 \text { 或 } g_{i} \geq D 3 \\
\frac{g_{i}-D 1}{D 2-D 1} & D 1<g_{i}<D 2 \\
1 & g_{i}=D 2 \\
\frac{D 3-g_{i}}{D 3-D 2} & D 2<g_{i}<D 3
\end{array}\right.
\end{gathered}
$$

$$
r_{i 4}= \begin{cases}0 & g_{i} \leq D 3 \text { 或 } g_{i} \geq D 5 \\ \frac{g_{i}-D 3}{D 4-D 3} & D 3<g_{i}<D 4 \\ 1 & g_{i}=D 4 \\ \frac{D 5-g_{i}}{D 5-D 4} & D 4<g_{i}<D 5\end{cases}
$$

$$
r_{i 5}= \begin{cases}0 & g_{i} \leq D 4 \\ \frac{g_{i}-D 4}{D 5-D 4} & D 4<g_{i}<D 5 \\ 1 & g_{i} \geq D 5\end{cases}
$$

\section{5 模糊综合评价模型的构建}

根据隶属函数, 计算出各指标对应各等级的隶属 度, 构成 $i \times j$ 阶隶属关系矩阵 $R$ 。将上述计算得到的 综合权重向量 $\mathrm{A}$ 与模糊关系矩阵 $\mathrm{R}$ 进行模糊合成运 算, 得到模糊综合评价结果向量 $\mathrm{B}$ 。对结果向量 $\mathrm{B}$ 取 最大值 $\operatorname{grid}_{\text {max }}$, 则 grid $_{\text {max }}$ 隶属于评判集中的某个等级, 就得到所需要模糊综合评价等级, 即洪涝灾害风险等 级。再将向量 $\mathrm{B}$ 所对应等级的序加权求平均, 得到 grid $_{\text {mean }}$, 即洪涝灾害风险指数。

$$
\begin{aligned}
& \operatorname{grid}_{\text {max }}=\max (\mathrm{B}) \\
& \operatorname{grid}_{\text {mean }}=\sum \text { grid }_{\text {max }} \times j / \sum \text { grid }_{\text {max }}
\end{aligned}
$$




\section{4. 结果与分析}

\section{1 安徽沿江地区洪涝灾害风险空间分布特征}

基于 GIS 空间分析技术，栅格大小为 $100 \mathrm{~m} \times$ $100 \mathrm{~m}$, 运用模糊综合评价方法进行评价, 得到安徽沿 江地区洪涝灾害风险指数图 (图 1), 运用最大隶属度 法确定洪涝灾害风险等级 (图 2)。

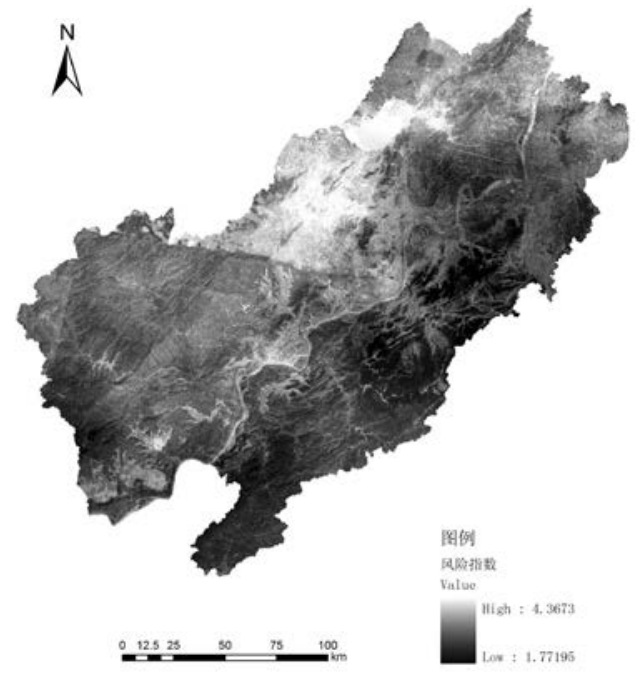

图 1 安徽省沿江地区洪涝灾害风险指数 Fig.1 Flood risk index along Yangtze River in Anhui province

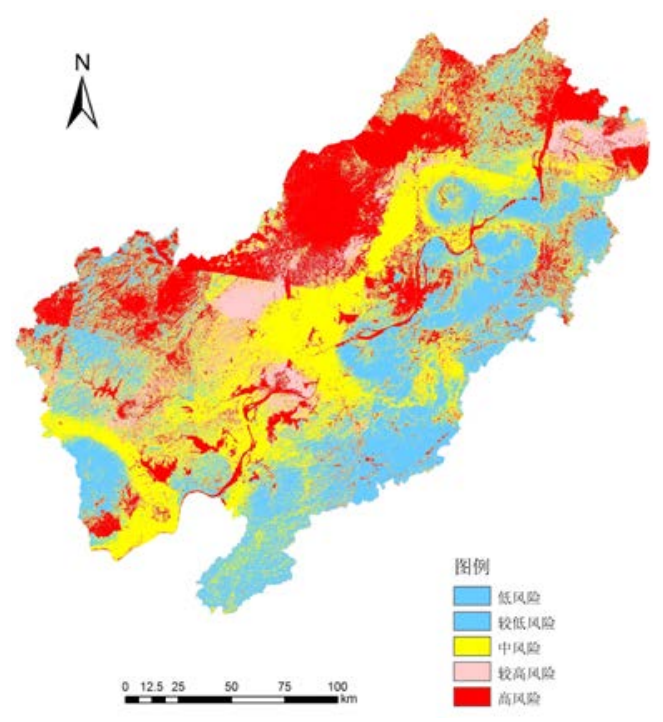

图 2 安徽省沿江地区洪涝灾害风险等级

Fig.2 Flood risk rank along Yangtze River in Anhui province

从空间分布格局上来看, 安徽沿江地区洪灾风险 等级和风险指数均有自南向北逐渐增加的趋势。高风 险区主要集中在北部和沿江干流两侧的区域, 该区地 势低平、经济易损性相对较高、河网密度较大、耕地 面积比重大, 遭受洪涝灾害威胁的可能性就相对较大。
低风险区主要集中分布于皖南山地区和西部部分地 区, 该区地形起伏较大、植被覆盖状况良好、经济发 展水平相对较低、耕地面积比重小, 遭受洪涝灾害威 胁的可能性相对较小。

从风险等级构成上（图 2) 来看, 安徽沿江地区 高风险区面积约 $11225.3 \mathrm{~km}^{2}$, 占区域总面积的 $28.76 \%$, 较高风险区所占比例较小, 为 $8.92 \%$, 约 $3481 \mathrm{~km}^{2}$ 。中 风险区、较低风险区及低风险区所占面积比例依次为 $23.01 \%$ 、20.15\% 和 $19.16 \%$ 。

\section{2 安徽沿江地区各县（市）洪涝灾害风险分布特征}

从各个县 (市) 的风险等级构成来看，马鞍山市、 庐江县、铜陵市、巢湖市、岳西及潜山县的高风险区 占县市面积的 $50 \%$ 以上, 政府应加强对洪涝灾害的预 警及抵御工作。池州市、东至县、石台县、青阳县的 高风险区面积比例均低于 $10 \%$, 且低风险所占面积比 重较大, 说明其遭受洪涝灾害威胁的可能性较小。怀 宁县、安庆市、宿松县、枞阳县、无为县的中风险区 比例超过 $40 \%$ 以上，且高风险区及低风险区比例和不 超过 $30 \%$, 说明其遭受洪灾的可能性一般。

从各个县 (市) 的风险指数均值来看, 区域内各 县（市）的平均风险指数差异不大，均处于中等风险 水平和较高风险水平。属于较高风险水平的县（市） 有庐江县、巢湖市、马鞍山市、桐城市、含山县、安 庆市、枞阳县、和县、怀宁县、当涂县、潜山县、岳 西县、望江、县、铜陵市、太湖县、无为县, 平均风 险指数依次为 $3.726 、 3.522 、 3.381 、 3.375 、 3.351 、 3.342$ 、 $3.323 、 3.294 、 3.214 、 3.200 、 3.182 、 3.134 、 3.117$ 、 $3.046 、 3.033 、 3.012$; 属于中等风险水平的有芜湖市、 石台县、宿松县、芜湖县、池州市、铜陵县、东至县、 南陵县、繁昌县、青阳县, 平均风险指数依次为 2.988 、 $2.891 、 2.873 、 2.811 、 2.762 、 2.734 、 2.723 、 2.713 、$ $2.676 、 2.612$ 。

\section{5 结论}

运用层次分析法和熵权法求算综合权重，构建模 糊综合评价模型，并结合 GIS 空间分析技术，绘制了 安徽沿江地区洪涝灾害风险指数图和风险等级图, 对 安徽沿江地区洪涝灾害风险的空间分布特征得到了较 为全面的认识。应用 GIS 空间分析技术和栅格计算方 法, 大大地提高了分析的精度。如果进一步选取评价 指标, 提高网格精度和社会经济数据空间展布精度, 安徽沿江地区洪涝灾害风险格局研究会更有意义。今 后应结合遥感等实时数据及 $3 \mathrm{~S}$ 技术, 模拟人类活动 干扰下洪涝灾害风险发展过程, 可视化表达洪涝灾害 灾害风险, 实现洪涝灾害风险的动态评估。 


\section{致谢}

本研究得到了国家自然科学基金项目(41271516)资助。

\section{参考文献}

1. Shi Peijun. Theory on disaster science and disaster dynamics[J]. Journal of Natural Disasters,2002,11(3):1-9. 史培军. 三论灾害研究的理论与实践 [J]. 自然灾害学 报,2002,11(3):1-9.

2. Dilley M, Chen R.S, Deiehmann U, et al. Natural disaster hotspots: A global risk analysis synthesis report[R]. Washington D C: Hazard Management Unit, World Bank, 2005.

3. Apel H, Thieken A H, Merz B, et al, Flood risk assessment and associated uncertainty[J]. Natural Hazards and Earth System Sciences, 2004 (4):295-308.

4. Maxx D, Robert S C, Uwe D, et al. Natural disaster hotspots: A global risk analysis[R]. World Bank,2005.

5. Islam A E, Elsayed H , Mohammed E B, GIS-modelling of the spatial variability of flash flood hazard in A bu dabbab catchment, red sea region, Egypt[J]. The Egyptian Journal of Remote Sensing and Space Sciences,2010 (13):81-88.

6. Emlyn Hagen J F, Shroder J, Lu X X, et al, Reverse engineered flood hazard mapping in Afghanistan: A parsimonious flood map model for developing countries[J].Quaternary International ,2010 (226):82-91.

7. Zhang Hui, Zhang Jiquan, Han Junshan. GIS-based assessment and zoning of flood/waterlogging disaster risk: a case study on $m$ iddle and lower reaches of Liaohe River[J]. Journal of Natural Disasters, 2005,14(6):141-146. 张会,张继全,韩俊山. 基于 GIS 技术的洪涝灾害风险评估 与区划研究一以辽河中下游地区为例 [J]. 自然灾害学 报,2005,14(6):141-146.

8. Li Ning, Zhai Yaxin, Wang Wei, et al. A comprehensive method to evaluate flood disasters based on basyesian stochastic assessment method[J]. Journal of Beijing Union University (Natural Sciences), 2011, 25(3):70-73.

李宁,翟亚欣,王威,等. 基于贝叶斯随机评价方法的洪水 灾情等级评价[J].北京联合大学学报(自然科学版), 2011, 25(3):70-73.

9. Zou Qiang, Zhou Jianzhong, Zhou Chao, et al. Flood disaster risk analysis based on variable fuzzy set theory[J]. Transactions of the Chinese Society of Agricultural Engineering (Transactions of the CSAE), 2012, 28(5): 126-132.
邹强,周建中,周超,等. 基于可变模糊集理论的洪水灾害 风险分析[J]. 农业工程学报,2012,28(5):126-132.

10. Zhang Jingjing. Risk assessment and spatial-temporal distribution characteristics of flood and drought disasters in Henan province[J]. Transactions of the Chinese Society of Agricultural Engineering (Transactions of the CSAE), 2012, 28(18):98-106.

张竟竟.河南省农业水旱灾害风险评估与时空分布特征 [J].农业工程学报,2012,28(18):98-106.

11. Liu Xinli, Shi Peijun. The theory and application of model research of regional flood risk assessment[J]. Journal of Natural Disasters, 2001,10(5):66-72.

刘新立, 史培军. 区域水灾风险评估模型研究的理论与实 践 $[J]$.自然灾害学报,2001,10(5):66-72.

12. Jin Juliang, Zhang Libing, Wei Yiming. Application of genetic algorithm based on ideal interval method to evaluation of flood disaster loss[J]. Scientia Geographica Sinica, 2004,24(5):586-590.

金菊良,张礼兵,魏一鸣.基于遗传算法的理想区间法在洪 水灾情评价中的应用[J]. 地理科学,2004,24(5):586-590.

13. Huang Chongfu, Zhang Junxiang, Chen Zhifen, et al. Toward a new kind of natural disaster risk zoning map $[\mathrm{J}]$. Journal of Natural Disasters, 2004,13(2):9-15.

黄崇福,张俊香,陈志芬,等.自然灾害风险区划图的一个 潜在发展方向[J].自然灾害学报, 2004,13(2):9-15.

14. Wu Danwa,Yan Xiaojing. Mesoscale ch aracteristics analysis of a heavy rainfall along the Yangtze river regions in Anhui in 2010[J].Journal of Anhui Agri Sci, 2011,39(5):2756-2759

吴丹娃,严小静.2010 年安徽沿江地区一次暴雨的中尺度 特征分析 [J].安徽农业科学.2011,39(5):2756-2759.

15. Zhang Zhili. Disaster analysis and management planning in polder area along the Yangtze River in Anhui province[J].Journal of Hydraulic Engineering, 1981,3:56-61.

张之丽. 安徽沿江圩区灾害成因分析及治理规划意见 [J]. 水利学报,1981,3:56-61.

16. Zhu Weimin,Huang Shixiang,Fan Dongguang. Law and trend of drought/flood in the region along the Yangtzer river of Anhui[J]. Journal of Anhui Agricultural University, 1988(3):43-49.

朱维民,黄世祥,范东光.安徽沿江地区旱涝规律及其未来 趋势 [J]. 安徽农学院学报, 1988(3):43-49.

17. Zhang Haiyu, Cheng Xianfu, Ma Wu. Fuzzy assessment of the vulnerability risk of flood disaster: a case study on area along the Yangtze River in Anhui province[J]. Journal of Catastrophology, 2010,25(1):30-34.

张海玉, 程先富,马武,洪涝灾害经济易损性模糊评价一 以安徽沿长江地区为例 [J]. 灾害学. 2010, 25(1):30-34 